\title{
Epidemiology of Tattoos in Industrialized Countries
}

\author{
Nicolas Kluger \\ University of Helsinki and Helsinki University Central Hospital, Dermatology, Helsinki, Finland
}

\begin{abstract}
In 1974, the first professional French tattooist C. Bruno wrote a book, entitled 'Tatoués, qui êtes-vous?', depicting his experience as a tattooist in the picturesque Pigalle tourist district of Paris. However, we have come a long way since then. Tattooing has gained tremendous visibility, notoriety and popularity in Western countries. In Germany, $8.5 \%$ of the population (aged between 14 and 90 years) has a tattoo. Similar trends have been found in France, Finland and Australia, where approximately $10 \%$ of the populations have at least one tattoo. However, the overall tattoo prevalences overseas and in Europe are even higher, especially among the youth, for whom it is up to $15-25 \%$ according to the country. Much has been written about the tattooed and tattooists. However, who are they currently? What motivates them to get tattooed and give tattoos? How do they see themselves? Why do some individuals remove their tattoos? Is there a 'profile' of the tattooed? Are they really 'risk takers'? And how do the nontattooed perceive them? Through a critical review of the literature, we will reconsider tattooing from an epidemiological aspect, challenge current beliefs and explore new insights into the motivations and fears of tattoo artists and their clients. @ 2015 S. Karger AG, Basel
\end{abstract}

For the past 20 years, body art, mainly tattooing and piercing, has gained tremendous popularity and visibility in Western countries. Until quite recently, we had only limited data on the absolute prevalence of tattooing and piercing practices [1]. Recently, these practices have become the center of interest, and publications have flourished. This interest has included not only the prevalence of but also motivations for getting tattooed and the perceptions of tattooed individuals by other nontattooed subjects in addition to their self-perceptions. We review here the epidemiology of tattooed individuals in Western countries.

\section{Tattooing as a Trademark of the $X$ and Millennial Generations}

Whether studies have been performed in the USA, in Europe or in Australia, the overall prevalence of tattooing is around $10-20 \%$ [2-12]. Results have varied according to the studied population, the country of origin and the time when the studies were performed. Currently, the 'elder' generations, known as the 'Boomers' and the 'Silent' Generation (especially individuals over 45 and 65 years of age), are clearly less tattooed than the young [5]. This 
observation is explained by the fact that getting tattooed in the 1950s-1960s was far from being mainstream and was definitely not accepted by the middle classes in the USA and in Europe [13]. Tattoos were then associated with sailors, the military, criminals, prostitutes and other marginal groups [13]. It is not surprising that in 2006, Stirn et al. reported 'only' an $8.5 \%$ prevalence of tattooed individuals in Germany in a study including individuals up to 90 years of age [8]. In their national survey in 2004, Laumann et al. clearly showed that the current tattooed generation was born at the end of the 1970 s - beginning of the 1980s [2]. The prevalence was the highest among individuals between 18 and 29 years of age [2]. Interestingly, 8 years later, in 2012, the Harris Poll Interactive confirmed that the very same group (now aged 30-39) was still the predominant tattooed group in the USA [6].

The prevalence of tattooing in the general population is rising. The Harris Polls, which were performed successively in 2003, 2008 [4] and 2012 [6], reported an overall increase in tattooing from 2003 to 2012 for the general population, and for the men and women, prevalences increased by $16 \%, 16$ and $15-21 \%, 19$ and $23 \%$, respectively [6].

Tattooing definitely belongs to Generation X and is a part of the Millennial Generation, mainly those born at the beginning of the 1980s [5]. It is still too early to know whether the next generation and the youngest group of the Millennial Generation will follow the tattooing trend as eagerly as the previous one. One could expect a decrease as a form of defiance and rejection against such trends belonging to the previous generation.

\section{Are There More Tattooed Women than Men?}

Traditionally, tattooing has been more prevalent among men, or at least it has been more accepted for a male to be tattooed than a female, as we will see below. Consequently, the numbers of women with tattoos used to be fewer than those of tattooed men (table 1). As illustrated in Australia, tattooing is more common among older age groups, particularly in men over 40 years of age [12]. However, over the past 20 years, this trend has progressively changed. In the beginning of the 1990s, half of all tattoos were already being performed on women from every social class [14]. The incidence of tattoos among women has quadrupled, and today, the figures for the two genders approach equality [5]. In some studies, the trend has even inverted. In the USA, the prevalence of tattooed women has surpassed that of tattooed men (23 vs. 19\%) [6]. In Australia, men are significantly more likely to be tattooed than women (15.4 vs. $13.6 \%$ ) [12]. However, among individuals 20-29 years of age, tattooed women clearly predominate in Australia (29.4 vs. 22.3\%) [12].

The choice of a tattoo is also guided somewhat by gender $[1,15]$. Men often have multiple tattoos located mainly on the arms and upper back and on an exposed area. In contrast, women tend to choose more discrete, less visible, smaller and unique tattoos $[1,15]$. However, the visibility of tattoos is variable. According to the Pew Research Center [5], over $70 \%$ of interviewed individuals reported that their tattoos were not usually visible. Visibility may, however, depend on the clothing worn [5].

Cosmetic tattoos (or permanent make-up) are usually performed on the faces of women (eyelids, eyebrows, and lips) for various reasons. It is not clear whether those tattoos are always included in studies or not, but they are an additional explanation of the increased prevalence of tattooing among women, both young and old [16].

The impact of peer influence is quite important. Indeed, $75 \%$ of young tattooed individuals have at least one close friend who is tattooed, and $29 \%$ have at least one immediate family member with tattoos [17]. Moreover, the number of tattoos is significantly related to the number of friends with tattoos, supporting the role of the friendship network [18]. Family influence is rather limited and at most weak. A correlation between the number of tattoos and the number of 
Table 1. Prevalence of tattoos among adults in several industrial countries

\begin{tabular}{|c|c|c|c|c|c|c|}
\hline Country/population & Year & $\mathrm{N}$ & Age, years & $\%$ & Men, \% & Women, \% \\
\hline $\begin{array}{l}\text { North America } \\
\text { USA } \\
\text { Random phone interview [2] }\end{array}$ & 2004 & 500 & $\begin{array}{l}18-50 \\
18-29 \\
30-40 \\
41-50\end{array}$ & $\begin{array}{l}24 \\
36 \\
24 \\
15\end{array}$ & 26 & 22 \\
\hline $\begin{array}{l}\text { USA } \\
\text { Internet survey [3] }\end{array}$ & 2008 & 452 & $\begin{array}{l}\text { Total } \\
18-49 \\
50-69\end{array}$ & $\begin{array}{l}- \\
- \\
-\end{array}$ & $\begin{array}{r}- \\
18 \\
16\end{array}$ & $\begin{array}{r}- \\
29 \\
7\end{array}$ \\
\hline $\begin{array}{l}\text { USA } \\
\text { National representative on-line poll } \\
\text { (Harris Poll) [4] }\end{array}$ & 2008 & 2,302 & $\begin{array}{l}\text { Total } \\
18-24 \\
\mathbf{2 5 - 2 9} \\
30-39 \\
40-49 \\
50-64 \\
65-\end{array}$ & $\begin{array}{r}14 \\
9 \\
32 \\
25 \\
12 \\
8 \\
9\end{array}$ & 15 & 13 \\
\hline $\begin{array}{l}\text { USA } \\
\text { National representative on-line poll } \\
\text { (Harris Poll) [6] }\end{array}$ & 2012 & 2,016 & $\begin{array}{l}\text { Total } \\
18-24 \\
25-29 \\
30-39 \\
40-49\end{array}$ & $\begin{array}{l}21 \\
22 \\
30 \\
38 \\
27\end{array}$ & 19 & 23 \\
\hline $\begin{array}{l}\text { Europe } \\
\text { France } \\
\text { Nationally representative } \\
\text { phone interview [7] }\end{array}$ & 2010 & 958 & $\begin{array}{l}\text { Total } \\
18-24 \\
\mathbf{2 5 - 3 4} \\
35-49 \\
50-64 \\
65-\end{array}$ & $\begin{array}{r}10 \\
8 \\
\mathbf{2 0} \\
12 \\
5 \\
1\end{array}$ & $\begin{array}{l}11 \\
- \\
- \\
- \\
- \\
-\end{array}$ & $\begin{array}{l}9 \\
- \\
- \\
- \\
- \\
-\end{array}$ \\
\hline $\begin{array}{l}\text { France } \\
\text { Random youth leaving a bar on } \\
\text { Saturday night [50] }\end{array}$ & 2012 & 1,965 & $\begin{array}{l}\text { Total (mean } \\
\text { age: } 20-22 \\
\text { years) }\end{array}$ & 17 & 11.5 & 24 \\
\hline $\begin{array}{l}\text { Germany } \\
\text { Face-to-face interview at home [8] }\end{array}$ & - & 2,043 & $\begin{array}{l}\text { Total } \\
14-44 \\
25-34\end{array}$ & $\begin{array}{l}8.5 \\
15 \\
-\end{array}$ & $\begin{array}{c}- \\
- \\
22\end{array}$ & $\begin{array}{l}- \\
- \\
-\end{array}$ \\
\hline $\begin{array}{l}\text { Finland } \\
\text { Youth barometer [9] }\end{array}$ & 2009 & 1,898 & $\begin{array}{l}\text { Total }(15-29) \\
15-19 \\
20-24 \\
\mathbf{2 5 - 2 9}\end{array}$ & $\begin{array}{r}13 \\
9 \\
12 \\
19\end{array}$ & - & - \\
\hline $\begin{array}{l}\text { Australia } \\
\text { Random sample survey [10] } \\
\text { Random phone interviews [11] } \\
\text { Random phone interview [12] }\end{array}$ & $\begin{array}{l}1998 \\
2001-2002 \\
2004-2005\end{array}$ & $\begin{array}{r}10,030 \\
19,000 \\
8,656\end{array}$ & $\begin{array}{l}>14 \\
16-59 \\
\text { Total }\end{array}$ & $\begin{array}{l}10 \\
12.6 \\
14.5\end{array}$ & $\begin{array}{c}- \\
14.5 \\
15.4\end{array}$ & $\begin{array}{c}- \\
10.6 \\
13.6\end{array}$ \\
\hline
\end{tabular}

Bold values indicate the age group where the prevalence of tattooed individuals is the highest. 
family members with tattoos has been noted [17]. Among family members, sisters have the highest influence [18].

According to Laumann et al., $65 \%$ of tattooed individuals got their first one before the age of 24 years [2], and in Germany, Stirn et al. found that $77 \%$ of individuals were tattooed before the age of 35 years [8]. In approximately $90 \%$ of cases, tattoos are performed in a professional tattoo shop [2]. In a rather limited number of cases (2.7-3.2\%), they are performed at 'home' (home tattooing) $[12,19]$.

In 2009, a nation-wide internet-based survey was performed on German-speaking individuals that recruited 3,411 tattooed participants [19]. This study gave a fairly interesting snapshot of the 'typical' west European tattooed individual at the end of the first decade of the 2000s [19]. Overall, the mean age of the tattooed subjects was 30 years. They possessed professional tattoos (96\%), usually one to 3 tattoos (73\%), and many were of a single color (63\%), typically black (59\% of cases). These tattoos covered more than $300 \mathrm{~cm}^{2}$ of the surface of the skin in $61 \%$ of the cases. The first tattoo was typically acquired during early adulthood, between the ages of 18 and 35 years (77\%) was rarely acquired as a minor $(17.6 \%$ were minors when they were first tattooed). Women tended to have tattoos on the trunk (54\%), and men had more on the arms (48\%). However, these results may be overestimates of the true values because this study selected tattooed aficionados who were more willing to participate and were more likely into tattoos. Tattooing was rarely performed at home (2.7\%).

It's not possible to construct a general 'profile' of tattooed individuals because everyone is unique. However, several groups of subjects with tattoos sharing similar characteristics have been reported. Latreille et al. succeeded in defining 4 profiles of tattooed individuals based on a series of 151 consecutive French subjects asking for tattoo removal [15]. Of course, it is pointless and meaningless to try at all costs to put every tattooed individual into one of these groups. How- ever, these data are of interest in terms of information campaigns about tattooing and tattoo removal to avoid unwanted tattoos, disappointment and unnecessary removal procedures. They are also useful in terms of creating more homogeneity with homogenous groups of tattooed subjects for further epidemiological studies. The four groups are summarized in figure 1.

\section{Tattooing among Adolescents}

Adolescents, e.g. high-school students under 18 years of age and college students, are undoubtedly the most studied group of interest (table 2). Studies have focused on subjects over 18 years of age [18] and under 18 years of age [20], disclosing different results. Tattooed adolescents see themselves as 'risk takers' [21]. They do not always seek advice nor inform their parents that they are getting a tattoo [22]. They may undergo tattooing despite not being allowed to by their parents [23]. According to a recent study in Naples, Italy, 73\% of high-school students had body art that had been performed in unauthorized facilities [24]. There is a lack of perception of the possible risks related to body art, which indicates the need for proper information on body art-related health risks among adolescents [22, 24-26].

According to several North American studies [20, 27-30], body art, including tattooing, is associated with various risk-taking behaviours, such as substance use (cannabis, alcohol, and antidepressants) [27, 30], sexual activity, violent behaviour and school problems in adolescent populations aged 12-18 [20], 12-22 [28], and 11-21 [29]. Laumann et al. also have noted that a first tattoo acquired before the age of 18 years is associated with a time in jail of more than 3 days and the use of recreational drugs [2]. The age of acquisition of body art is related to a higher risk of the use of getaway drugs [28], as well as the receipt of amateur tattoos [28]. Nevertheless, other factors, such as the receipt of parental consent before 
Fig. 1. Tattooed individuals' characteristics grouped into 4 types, according to Latreille et al. [15].

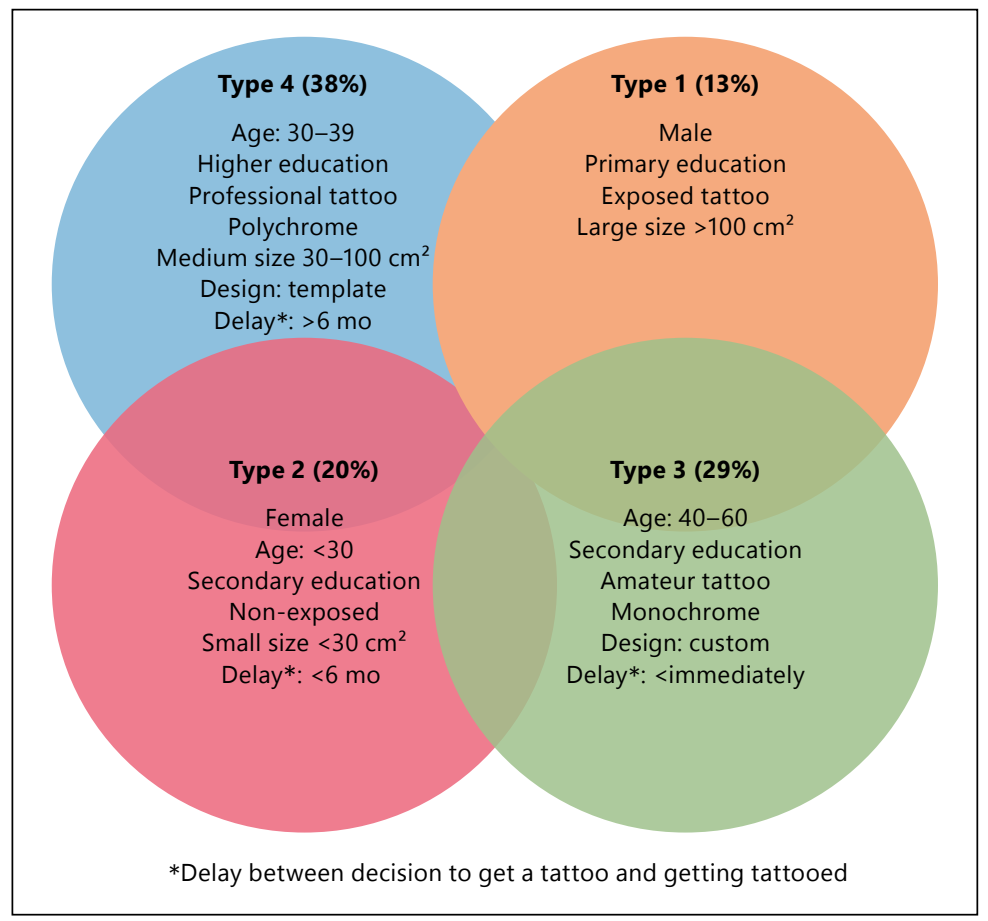

obtaining a tattoo, a tattoo's meaning, and its location may come into account. Tattooing among high-school students and adolescents under the age of 18 years may be used as an indicator of risk behaviours.

\section{Other Populations}

Other populations have been studied regarding tattoos. Because they have been highly selected, results cannot be interpreted in any light other than the context in which they have been applied. Naturally, the same logic applies to the possible psychopathological implications of tattooing [31].

Although tattooing is illegal in most prisons throughout the world, it has completely integrated into the lifestyles of inmates. Tattoos may have been applied before imprisonment [32]. Of note, if tattoos are acquired in the community, a backyard tattooist or friend is rather frequently used [33]. Tattoos are more often applied during imprisonment for various reasons, including prison culture, protection, signs of strength and aggressiveness, remembrance, passing time/ boredom, particular personality types or just because the prisoner liked tattoos [31,33]. The prevalence of tattooed inmates is variable according to previous studies. It has been estimated that almost $40 \%$ of inmates get tattooed while in prison [32]. Results have differed according to the country. In Marseilles, France, $8.9 \%$ of inmates reported having been tattooed during the first 3 months of imprisonments [34]. In Chicago, Illinois, $66 \%$ of inmates have tattoos, but only $16 \%$ received them during incarceration [33]. In Victoria, Australia, 70\% of prisoners have been tattooed, and $41 \%$ of them have been tattooed while in prison [32]. The main risk of prison tattooing is the transmission of bloodborne diseases, mainly hepatitis $\mathrm{C}$, due to a lack of hygiene and asepsis [32-34], implying that 
Table 2. Prevalence of tattooing among adolescents in several industrial countries

\begin{tabular}{|c|c|c|c|c|c|c|}
\hline Country/population & Year & $\mathrm{N}$ & $\begin{array}{l}\text { Age range (years) } \\
\text { or mean age }\end{array}$ & $\%$ & $\begin{array}{l}\text { Boys } \\
\text { (\%) }\end{array}$ & $\begin{array}{l}\text { Girls } \\
(\%)\end{array}$ \\
\hline $\begin{array}{l}\text { North America } \\
\text { USA } \\
\text { Military beneficiaries attending } \\
\text { an adolescent clinic [28] }\end{array}$ & $2000-2001$ & 552 & $12-22$ & 13.2 & 8.1 & 16.6 \\
\hline $\begin{array}{l}\text { USA } \\
\text { School-based national representative } \\
\text { sample [29] }\end{array}$ & 1995-1996 & 5,837 & $11-21$ & 4.6 & 4.8 & 4.2 \\
\hline $\begin{array}{l}\text { Canada } \\
\text { High schools, Quebec, Canada } \\
{[20]}\end{array}$ & 2002 & 2,145 & $\begin{array}{l}12-18 \\
12-13 \\
14-15 \\
16-18\end{array}$ & 8 & $\begin{array}{l}5.8 \\
4 \\
4.9 \\
8.5\end{array}$ & $\begin{array}{r}9.8 \\
3.5 \\
7.6 \\
18.1\end{array}$ \\
\hline $\begin{array}{l}\text { Europe } \\
\text { Questionnaire administered at high } \\
\text { schools, Naples, Italy [24] }\end{array}$ & 2008-2009 & 9,322 & Mean age 16.1 & 11.3 & 11.7 & 10.9 \\
\hline $\begin{array}{l}\text { Questionnaire administered at a } \\
\text { university in the province of Naples [24] }\end{array}$ & 2008-2009 & 3,610 & Mean age 21.6 & 24 & 15.1 & 20.7 \\
\hline $\begin{array}{l}\text { Questionnaire administered at public } \\
\text { secondary schools, Veneto, Italy [25] }\end{array}$ & - & 4,277 & $14-22$ & 6 & - & - \\
\hline $\begin{array}{l}\text { Anonymous written questionnaire } \\
\text { self-administered to freshmen, } \\
\text { University of Bari, Italy [22] }\end{array}$ & 2009-2010 & 1,598 & 20.1 & 9.6 & 9 & 9.8 \\
\hline $\begin{array}{l}\text { Other } \\
\text { Brazil } \\
\text { Examination of 18-year-old military } \\
\text { recruiters (male) [23] }\end{array}$ & 2010 & 1,968 & 18 & 10.8 & & - \\
\hline
\end{tabular}

prison administrations should take action to promote safe tattooing in prisons [35].

The military has been long reported as a subgroup for which tattoos are more frequently encountered. Tattoos may be performed by professional tattooists from the countries of origin of soldiers, abroad or more rarely, during deployment [36]. They are less frequently self-administered or performed by a friend [37]. They are usually performed in the context of peer group pressure [37]. The prevalence of tattoos ranges from $10 \%$ [23] to $44 \%$ [37-39]. The most common tattoo is a person's name [36]. However, in everyday practice, numerous French military individuals have been encountered with tattoos depicting their army corps. Currently, tattooing may be seen as a means of self-expression [36].

The body images of modern elite athletes have recently become important. An athlete's image reflects his or her identity and social, cultural and/or ethnic backgrounds. Most athletes follow current trends. Therefore, body art has gained increased popularity among athletes. Limited data are available on the true prevalence and incidence of body art among athletes. Benjamins et al. have reported a prevalence of $8.6 \%$ 
for minority high-school athletes with tattoos [40]. Broadcasting and advertisements clearly show elite athletes harboring tattoos who participate in various sports, such as football, rugby and swimming.

The possible association between tattoos (and piercing) and eating disorders (anorexia nervosa, bulimia, or binge-eating disorders) has been raised by Carroll et al. [28]. However, thus far, this link appears to be at most low/modest [28, 41] and has not been confirmed [42]. Moreover, tattooing in this peculiar population could be seen as a sign of self-care and body image improvement rather than self-harm [42].

\section{Background and Risk Factors among Tattooed Individuals}

The question of whether tattoos could be a sign of deviance or of 'risk behaviours' always raises tension among tattooed individuals. This reaction is often the consequence of misunderstandings of the frame and extent of the interpretation of studies. Moreover, in our experience, it is not rare that media report only fragments of select data or that they are misinterpreted before being published to an inexperienced public. Any study has to be read and interpreted carefully. The reader always must consider the following: who, where, how many and how? Indeed, the reader must consider the specificity of each population (ethnicity, teenager versus adult, prisoner, military, etc.) and also the methodology of the study (face-to-face interview vs. self-reported anonymous survey, internet survey, etc.), the number of individuals included and whether the conclusions are adequate. There are always numerous factors and biases, such as studies among teenagers (usually way more frequent) versus a more general and adult population, the inclusion of other pieces of body art (piercings, microdermals, transdermal piercings, etc.), the number of tattoos, their sizes, their locations and even tattoo designs. Overall, the results of cohort studies are not applicable to a given tattooed individual, and association does not mean causality.

\section{Education and Occupation}

There is no doubt that the current prevalence of tattooing has increased in all social groups $[2,14]$. However, tattooing remains more common among those of low socioeconomic and educational statuses $[2,12,15,23,43-46]$. The highest levels of education are associated with a diminished likelihood of being tattooed, especially in individuals who have completed secondary education [12]. In France, a difference in the working class is also notable. Up to $19 \%$ of workmen are tattooed, while only up to $7 \%$ of executives and $14 \%$ of middle managers are tattooed [7]. Stirn et al. have also reported that unemployment occurs significantly more often among tattooed individuals compared to controls [8].

\section{Marital Status and Sexuality}

Expressing sexual affectations or emphasizing sexuality through body art, tattooing or piercing, is a common motivation [13]. Clearly, piercing and tattoos can increase one's sexual attractiveness and sexual sensations. Popular beliefs have long related body art and piercing especially to male sexual orientation, sadomasochism or fetishism [45].

Individuals with tattoos are most often in a committed relationship, either living with a partner or being married or engaged similar to the general nontattooed population $[2,12,47]$. In Australia, tattooed women more often have a regular partner but do not live with them [12].

The sexual identity of either men or women is not associated with having tattoos $[12,45]$. In Australia, men and women with more lifetime sexual partners are more likely to have a tattoo [12]. 
Having a tattoo is associated with being sexually active for both men and women [48] and early sexual initiation (e.g. a younger age at initiating sex) $[45,48]$. Nowosielski et al. performed a study specifically focused on the sexual behaviours of young tattooed and/or pierced adults in Poland [45]. A younger age at first sexual intercourse and a higher number of lifetime sexual partners were observed among the tattooed participants. They may have more liberal attitudes towards sexuality, but importantly, tattooed adults do not engage in risky sexual behaviours. There was no statistical significance observed for the associations of tattoos with sexual preference, orientation, engaging in risky sexual behaviours, the frequency of masturbation or history of sexual abuse [45]. Recently, Swami corroborated that tattooed individuals are more likely to engage in sexual relations in the absence of commitment [49]. However, she also showed that this difference existed prior to obtaining a tattoo and therefore, this behaviour was not the result of tattoo procurement [49]. There is no difference in terms of sexually transmitted diseases between tattooed and nontattooed subjects [12]. Persons with tattoos should not be considered as belonging to a sexually transmitted infection risk group [45]. Of note, Stirn et al. [44] found among a group of 432 subjects with body art (piercings and tattoos) that $9 \%$ had reported to have been a victim of sexual abuse during childhood (7.4\%) or adulthood (1.4\%). These results were not found by Nowosielski et al. [45]. However, it is possible to regain a feeling of control over one's own body through body modifications [44].

\section{Behaviours: Smoking, Alcohol and Drug Use}

Tattooed individuals (men and women) more often disclose smoking habits compared to nontattooed individuals, as demonstrated by various studies in different countries $[3,12,23,43,46$, 50]. Not only smoking but also early smoking [50] and a higher level of daily cigarette consump- tion $[50,51]$ have been reported among youth. Having both piercings and tattoos is associated with an increase in smoking behaviours compared with having only tattoos [50].

The association of tattoos with alcohol consumption is far less clear-cut. It does not seem to be particularly increased among tattooed individuals in Australia [12]. According to Laumann et al., there are fewer 'never drinkers' among individuals with tattoos compared to those without them, and more tattooed individuals have a presumed drinking problem [2]. This same study reported a higher alcohol intake among tattooed individuals [2]. However, another self-reported study has reported that tattooed individuals are more frequently 'told to cut back alcohol,' although this finding was not statistically significant [3]. Tattooed adolescents report more binge drinking episodes than nontattooed adolescents [29]. Guégen has also observed that young French men and women with piercings and tattoos have higher levels of alcohol consumption on Saturday nights. However, adolescents with only tattoo(s) do not have higher levels than those who are nontattooed and nonpierced, which is suggestive of an association of cumulative body art with recreational alcohol consumption [52].

Recreational drug use (mainly cannabis use) has been reported to be more frequent among those with tattoos $[2,12]$. This behaviour has been found in both adults and adolescents $[28,29]$.

\section{Motivations to Get a Tattoo $[13,44]$}

The motivations that drive individuals to get one or more tattoos are plentiful. They have evolved from their primal uses for therapeutic purposes, as religious or subcultural group affiliation signs, as social status markers and as signs of strength [13] to simple fashion accessories. Understanding the motivations underlying the acquisition of tattoos is important to gain insights into the reasons why individuals modify their bodies and to contribute 
Table 3. Motivational categories according to Wohlrab et al. [13]

\begin{tabular}{l} 
Beauty, art and fashion \\
- Body embellishment \\
\hline Individuality \\
- Self-identity, distinction from others, and control of one's own appearance \\
\hline Personal narratives \\
- Expression of personal catharsis and personal values and reclamation of one's own body \\
\hline Physical endurance \\
- Testing one's own pain threshold during the procedure and it's limits \\
Group affiliations and commitments \\
- Subcultural memberships \\
\hline Resistance \\
- Resistance to society or to parents \\
\hline Spirituality and cultural traditions \\
\hline Addictions \\
- Physical addiction (endorphin release due to the pain experienced during the procedure) and \\
psychological addiction ('tattoo collectors')
\end{tabular}

Sexual motivations

No specific reasons

- Impulsive decision, sometimes under the influence of drugs or alcohol

to the elimination of the negative stigmatization of body modification [13]. Wolhrab et al. divided motivations for tattooing (and piercing) into ten categories, as summarized in table 3. It appears that several motivations may be combined for any given individual, and they may change over time according to the tattoo and the evolution of the individual and their environment. The embellishment of one's body and the search for individuality seem to be the main driving forces for obtaining a tattoo. Due to the permanence of tattoos, the time needed to plan them, painful tattooing session(s) and after-care, it is reductive to consider tattooing only as a fashion accessory. Tattoos contain deeper personal meanings [13]. More recently, the results of a study of 432 subjects have confirmed that overall, individuals acquire tattoos and/or piercings mainly to express individuality and self-consciousness and to demonstrate autonomy and bodily control. Rarely, individuals acquire tattoos to represent their belonging to a group or to be fashionable [44]. As Stirn et al. have stressed, currently, individuals want to be integrated into social environments and do not want to shock others. The Pew Research Center indirectly confirmed this point in their study, in which most adults (72\%) acknowledged that they did not want to display their tattoos in public [5]. However, Stirn et al. observed that individuals with a higher number of body art modifications (tattoos and piercings) would be looking to shock others, provoke rejection, experience pain and feel that they are doing what they want with their body [44]. These very same individuals with high numbers of body modifications have also reported an addiction to body art and a desire to acquire more [44]. Moreover, some individuals who have reported past sexual abuse may see and use body art as an attempt to overcome their experience and reclaim their body. However, the efficacy of body 
art in this regard is debatable, as illustrated by those individuals who continually accumulate additional modifications [44].

\section{How Do Tattooed Individuals See Themselves?}

Among those with tattoos, $30 \%$ feel sexier. Twenty-five percent find that tattoos make them feel more rebellious, $21 \%$ more attractive or strong, $16 \%$ more spiritual and 9\% healthier [6]. Only a limited number of tattooed individuals had opposite feelings about being tattooed (approximately 3\%) [6]. However, the feelings of being sexier, more rebellious and more attractive were diminished when these findings were compared to the results from the same poll performed in 2003 [6]. The fact that less tattooed individuals currently feel more rebellious can be explained by the increased popularity of tattooing. The self-assessment of attractiveness has been confirmed in other studies [53]. Tattooed individuals are usually more extraverted, more experience seeking, and more often have a need to be unique $[47,49,54]$. Not surprisingly, they also have more positive attitudes towards tattoos than nontattooed individuals [47]. Even though tattooed individuals rate themselves as more rebellious, recent studies have pointed out that there are no significant differences between tattooed and nontattooed individuals' attitudes towards authority [49]. This result is in opposition with the old belief that tattooing is an act of rebellion/gang affiliation or truancy. This discrepancy may be explained by differences in methodologies between self-reported behaviours and the use of specific scales [49].

\section{Tattoo Regrets and Reasons for Removal}

Tattooing is permanent by definition; however, the human mind is versatile. Regardless of the origin of and reason for getting tattooed, some indi- viduals will ultimately decide to have one of their tattoos removed. With the progression of removal techniques, the tattoo removal market has boomed within the past years.

However, the rate of regret may vary according to studied groups in terms of individuals' ages and interests (the general population, selected tattooed individuals, the military, etc.) and countries of origin, in addition to the time when the study was performed. Thus, in 2012, the Harris Poll reported that $14 \%$ of individuals regret getting a tattoo [6]. This proportion declined compared to the poll results from 2003 (17\%) [6]. Similarly, according to Laumann et al., 17\% have considered such a procedure (but had not yet received it at the time of the interview) [2]. One-third of British soldiers have acknowledged regretting their tattoos [37], while few have reported this regret in a very recent study of US military service members [36]. However, in studies performed on select groups of tattooed individuals, the rates of regret are lower. Indeed, Klügl et al. found that only $4.9 \%$ of tattooed individuals in a German-speaking country were not satisfied with their tattoos and were considering tattoo removal [19].

The reasons for tattoo removal are variable. The major reasons include never having been pleased with a tattoo, embarrassment or shame, and professional reasons [15]. Other motivations include the enhancement of self-esteem, social (change of lifestyle) and personal reasons (the tattoo feels incompatible with a patient's age or with their present attitudes/values), family pressure or a change of partner $[55,56]$. According to Latreille et al., almost $25 \%$ of subjects who attended their laser clinic where not immediately satisfied with their tattoo upon acquisition [15]. Among a collegiate tattooed population, $13 \%$ did not like their first tattoo, $18 \%$ found that the artist did not meet their expectations and $22 \%$ were not happy with one or more of their tattoos [18]. These results stress the importance of carefully planning a first tattoo and of choosing a professional tattooist with artistic qualities. 


\section{How Do Nontattooed Individuals See the Tattooed?}

Despite an obvious shift among the bearers of tattoos from marginal groups to the mainstream with tattooed individuals now being found in every social group, tattoos and tattooing are still associated with negative perceptions and connotations. According to the recent Harris Poll in 2012 [6], those without tattoos see people with tattoos as more rebellious (50\%), less attractive (45\%), less sexy (39\%), less intelligent (27\%), less healthy and less spiritual (25\%) [6]. Moreover, retrospective analysis of the same poll administered previously in 2003 and 2008 showed a lack of variation. A recent study performed in the 10 largest US cities confirmed these results [57]. Twenty-four percent still considered that tattooed individuals were more likely to have deviant behaviours [6]. Women pay the highest price for being tattooed [14]. In a study of British soldiers, $67 \%$ of those without tattoos found that tattoos on girls were 'not attractive' [37]. Women with visible tattoos are rated more negatively $[58,59]$, and the size of a tattoo appears to be a predictor of the attitudes of individuals without tattoos [59]. Swami et al. have shown that tattooed women are perceived as less physically attractive, more sexually promiscuous and heavy drinkers. The more tattoos present, the higher the negative rankings were [60]. It seems that the participants of these studies held conservative attitudes with regard to gender, believing that women with tattoos, e.g. women with liberal gender attitudes, were not acceptable and rating them negatively. Interestingly, Swami et al. have observed that ratings are more negative if a woman is blonde compared to brunette (!), showing the impact of physical stereotypes on the ratings of individuals [60]. Guéguen has also confirmed that men perceive women with a tattoo on the lower back as more easily engaging in sexual intercourse on a first date [61]. However, some studies have shown different results. For undergraduate students, only the credibilities of tattooed men and women are affected but not their levels of attractiveness [62]. In other studies, students have reported a positive or supportive image of tattooed people $[18,63]$.

Unfortunately, the overall negative stereotypes are not only harmful to individuals in terms of their self-esteem and relationships with others, they may also impact their professional activities. The attitudes of employers toward prospective employees may be influenced by visible tattoos [64]. Several studies have been conducted on health care service employees in the USA. Stuppy et al. were the first to report the overall negative ratings of tattooed individuals by physicians and nurses [65]. Women respondents viewed tattooed people less favorably and yet again, they rated tattooed professional women more negatively than their male counterparts. Overall, these negative stereotypes may negatively affect the management and care of tattooed patients. We have observed that female anesthesiologists more often have a negative opinion about tattoos compared to their male colleagues and tend to more frequently refuse epidural analgesia in parturients with lumbar tattoos [66]. If tattooed patients are perceived negatively by health care providers, then some patients are also likely to perceive tattooed health care personnel more negatively. Thus, the nurse with the most body art (piercings and visible tattoos) would be perceived as the least caring, skilled and knowledgeable [67]. Again, tattooed female nurses are perceived as less professional than males with similar tattoos [68].

\section{Tattooists}

Interestingly, specific data regarding tattooists are lacking. There is currently no formation or training that qualifies someone to become a 'tattooist'. As such, a 'tattooist' is not considered thus far as belonging to a specific profession. Traditionally, tattooing is learned by years of apprenticeship in a 


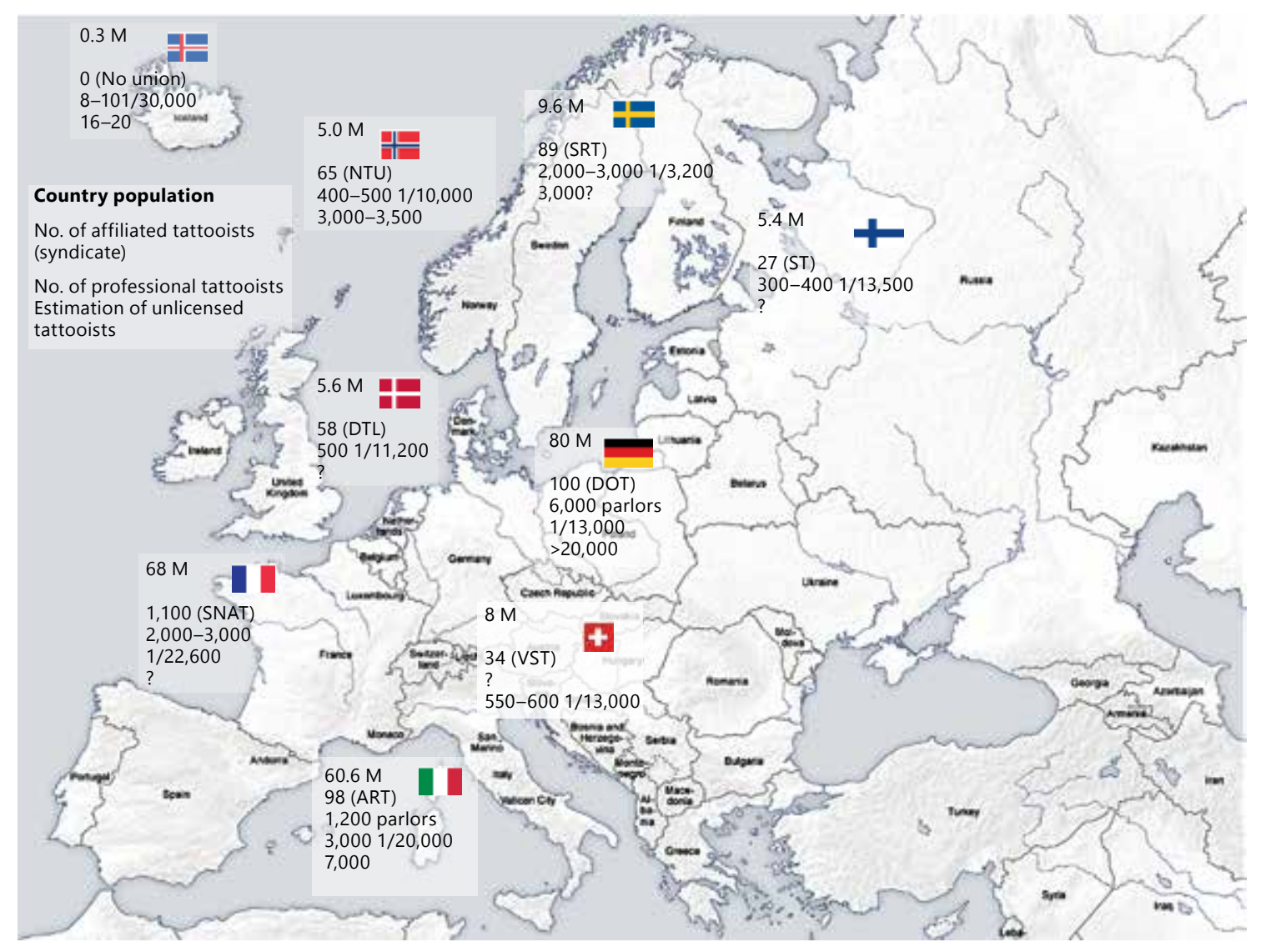

Fig. 2. Estimations of the numbers of tattooists in some European countries, including those belonging to a tattoo union, licensed tattooists and the estimated numbers of tattooists (including unlicensed ones) in 2013. Of note, the overall number of backyard/unlicensed tattooists is a self-estimation provided by tattoo unions upon request.

tattoo parlor in contact with experienced tattooist(s). Thus, tattooists are often 'self-educated'. Naturally, a tattooist needs to be gifted in the field of fine arts or plastic arts, although there are currently no schools that provide a 'tattooist' qualification. Virtually anyone can become a tattooist by buying tattooing materials and opening a tattoo shop as long the local legislation is respected. Such obligations vary according to the country. Because tattooists are often 'self-educated', it is important to insure for the safety of the customers and the tattooists themselves by providing them with a proper education and formation. In Western countries, despite the lack of legislation regarding the status of 'tattooist', tattooists have organized into unions/syndicates to promote tattooing and defend their rights as a specific profession. Meanwhile, national laws and legislation are starting to appear in an attempt to regulate this activity, ensure for the safety of customers and promote the proper functioning of the tattoo industry. For instance, in France, since 2009, tattooists have been obligated to be registered and to undergo training with regard to sepsis and hygiene. However, the tattoo industry has to face the rise of amateur or home tattooists (also called 'backyard tattooists' or 'scratchers'). The development of this market has been facilitated by the internet, which allows 
anyone to buy tattoo kits and inks. The tattoo industry considers them to be unfair competitors because unlicensed tattooists do not pay taxes or expenses related to parlor management. They usually can be found on the internet, providing inexpensive tattoos at home. In addition, home tattooing increases the risk of low-quality tattoos, which may lead to an increased number of tattoo removal procedures and an increased risk of infections because the sessions are not performed under adequate conditions of asepsis [69]. The real impact of this market is difficult to assess in terms of public health. Lastly, the proportion of allergic tattoo reactions that could be attributed to nonprofessional tattooing and the use of unauthorized inks is unknown. In figure 2, we summarize the number of 'official' tattooists in some European countries as well as an estimation of backyard tattooists, as determined by the tattoo syndicates.

\section{Conclusions}

Tattooing has grown in popularity and definitely belongs to the realm of generational conformity. Young adults and adults mainly see tattooing as a form of body art and not as a deviant behaviour
[18]. Caution is necessary when it comes to attributing psychopathology to tattooed adults [70]. However, for adolescents, tattoos could be a sign of risk behaviours. Unfortunately, tattooing remains associated with negative stereotypes that may impact the personal and professional lives of tattooed individuals.

The tattooed generation is now aged between 20 and 40 years (born from 1975 to 1990). The youth may not always perceive the risks of tattooing. The proper education of young customers and also of tattooists is mandatory to prevent complications. Moreover, this very same population will grow old and age with their tattoos. Physicians may expect to see more tattoo-related complications, whether they are related to tattooing or are just coincidental. The long-term issues related to tattoo inks are unknown. Lastly, some tattooed individuals will attempt to remove one of their tattoos. The long-term safety of lasers used for tattoo removal and the effects of the dispersion of tattoo ink by-products after laser treatment are unknown. The increase in tattoo removal procedures has led to an unregulated market of tattoo removal by cosmetologists, tattooists, nurses and nonspecialized physicians as well as of 'do-it-yourself tattoo removal procedures [71].

\section{References}

$>1$ Laumann AE: History and epidemiology of tattoos and piercings. Legislations in the United States; in De Cuyper C, Pérez-Cotapos ML (eds): Dermatologic Complications with Body Art. Berlin/ Heidelberg, Springer Verlag, 2010, pp 1-11.

2 Laumann AE, Derick AJ: Tattoos and body piercings in the United States: a national data set. J Am Acad Dermatol 2006;55:413-421.

3 Karagas MR, Wasson JH: A world wide web-based survey of nonmedical tattooing in the United States. J Am Acad Dermatol 2012;66:e13-e14.
4 Corso RA: Three in Ten Americans with a Tattoo Say Having One Makes Them Feel Sexier. Rochester, NY, Harris Poll, 2008. http://www.harrisinteractive.com/ vault/Harris-Interactive-Poll-ResearchThree-in-Ten-Americans-with-aTattoo-Say-Having-One-Makes-ThemFeel-Sexier-2008-02.pdf (accessed September 8, 2014).

5 Taylor P, Keeter S: Millennials: A Portrait of Generation Next: Confident. Connected. Open to Change. Washington, D.C., Pew Research Center, 2010. http://pewsocialtrends.org/ files/2010/10/millennials-confidentconnected-open-to-change.pdf (accessed September 8, 2014).
6 Braverman S: One in Five U.S. Adults Now Has a Tattoo. New York, NY, Harris Polls, 2012. http://www.harrisinter active.com/NewsRoom/HarrisPolls/ tabid/447/mid/1508/articleId/970/ctl/ ReadCustom\%20Default/Default.aspx (accessed September 8, 2014).

7 Fourquet J: Les Francais et les Tatouages. IFOP, 2010. http://www.ifop. com/?option=com_publication\&type = poll\&id=1220 (accessed September 8, 2014). 
8 Stirn A, Hinz A, Brähler E: Prevalence of tattooing and body piercing in Germany and perception of health, mental disorders, and sensation seeking among tattooed and body-pierced individuals. J Psychosom Res 2006;60:531-534.

9 Myllyniemi S: Taidekohtia: Nuorisobarometri 2009. Helsinki, Opetusministeriö, Nuorisotutkimusverkosto, Nuorisoasiain Neuvottelukunta, 2009. http://www.minedu.fi/ OPM/Nuoriso/nuorisoasiain_neuvotte lukunta/julkaisut/barometrit/liitteet/ Nuorisobarometri_2009.pdf (accessed September 8, 2014).

10 Makkai T, McAllister I: Prevalence of tattooing and body piercing in the Australian community. Commun Dis Intell Q Rep 2001;25:67-72.

11 Grulich AE, de Visser RO, Smith AM, Rissel CE, Richters J: Sex in Australia: injecting and sexual risk behaviour in a representative sample of adults. Aust N Z J Public Health 2003;27:242-250.

12 Heywood W, Patrick K, Smith AM, Simpson JM, Pitts MK, Richters J, Shelley JM: Who gets tattoos? Demographic and behavioral correlates of ever being tattooed in a representative sample of men and women. Ann Epidemiol 2012;22:51-56.

13 Wohlrab S, Stahl J, Kappeler PM: Modifying the body: motivations for getting tattooed and pierced. Body Image 2007; 4:87-95.

14 Armstrong ML: Career-oriented women with tattoos. Image J Nurs Sch 1991;23: 215-220.

15 Latreille J, Levy JL, Guinot C: Decorative tattoos and reasons for their removal: a prospective study in 151 adults living in South of France. J Eur Acad Dermatol Venereol 2011;25:181-187.

16 Armstrong ML, Saunders JC, Roberts AE: Older women and cosmetic tattooing experiences. J Women Aging 2009; 21:186-197.

17 Roberts AE, Koch JR, Armstrong ML, Owen DC: Correlates of tattoos and reference groups. Psychol Rep 2006;99: 933-934.

18 Armstrong ML, Owen DC, Roberts AE, Koch JR: College students and tattoos. Influence of image, identity, family, and friends. J Psychosoc Nurs Ment Health Serv 2002;40:20-29.

19 Klügl I, Hiller KA, Landthaler M, Bäumler W: Incidence of health problems associated with tattooed skin: a nationwide survey in German-speaking countries. Dermatology 2010;221:43-50.
20 Deschesnes M, Finès $P$, Demers $S$ : Are tattooing and body piercing indicators of risk-taking behaviours among high school students? J Adolesc 2006;29:379393.

21 Armstrong ML, McConnell C: Tattooing in adolescents: more common than you think-the phenomenon and risks. J Sch Nurs 1994;10:26-33.

22 Quaranta A, Napoli C, Fasano F, Montagna C, Caggiano G, Montagna MT: Body piercing and tattoos: a survey on young adults' knowledge of the risks and practices in body art. BMC Public Health 2011;11:774.

-23 Bicca JF, Duquia RP, Breunig Jde A, de Souza PR, de Almeida HL Jr: Tattoos on 18-year-old male adolescents - characteristics and associated factors. An Bras Dermatol 2013;88:925-928.

24 Gallè F, Mancusi C, Di Onofrio V, Visciano A, Alfano V, Mastronuzzi R, Guida M, Liguori G: Awareness of health risks related to body art practices among youth in Naples, Italy: a descriptive convenience sample study. BMC Public Health 2011;11:625.

25 Cegolon L, Miatto E, Bortolotto M, Benetton M, Mazzoleni F, Mastrangelo G; VAHP Working Group: Body piercing and tattoo: awareness of health related risks among 4,277 Italian secondary school adolescents. BMC Public Health 2010;10:73.

26 Majori S, Capretta F, Baldovin T, Busana M, Baldo V; Collaborative Group: Piercing and tatooing in high school students of Veneto region: prevalence and perception of infectious releated risk. J Prev Med Hyg 2013;54:17-23.

27 Braithwaite R, Robillard A, Woodring T, Stephens T, Arriola KJ: Tattooing and body piercing among adolescent detainees: relationship to alcohol and other drug use. J Subst Abuse 2001;13:5-16.

28 Carroll ST, Riffenburgh RH, Roberts TA, Myhre EB: Tattoos and body piercings as indicators of adolescent risk-taking behaviors. Pediatrics 2002;109:1021-1027.

29 Roberts TA, Ryan SA: Tattooing and high-risk behavior in adolescents. Pediatrics 2002;110:1058-1063.

30 Brooks TL, Woods ER, Knight JR, Shrier LA: Body modification and substance use in adolescents: is there a link? J Adolesc Health 2003;32:44-49.

-31 Manuel L, Retzlaff PD: Psychopathology and tattooing among prisoners. Int J Offender Ther Comp Criminol 2002;46: 522-531.
32 Hellard ME, Aitken CK, Hocking JS: Tattooing in prisons - not such a pretty picture. Am J Infect Control 2007;35: 477-480.

33 Abiona TC, Balogun JA, Adefuye AS, Sloan PE: Body art practices among inmates: implications for transmission of bloodborne infections. Am J Infect Control 2010;38:121-129.

-34 Rotily M, Delorme C, Obadia Y, Escaffre N, Galinier-Pujol A: Survey of French prison found that injecting drug use and tattooing occurred. BMJ 1998;316:777.

35 Gagnon H, Godin G, Alary M, Lambert G, Lambert LD, Landry S: Prison inmates' intention to demand that bleach be used for cleaning tattooing and piercing equipment. Can J Public Health 2007;98:297-300.

-36 Lande RG, Bahroo BA, Soumoff A: United States military service members and their tattoos: a descriptive study. Mil Med 2013;178:921-925.

37 Gadd MC: A survey of soldiers' attitudes to tattooing. J R Army Med Corps 1992; 138:73-76.

38 Armstrong ML, Murphy KP, Sallee A, Watson MG: Tattooed Army soldiers: examining the incidence, behavior, and risk. Mil Med 2000;165:135-141.

39 Stephens MB: Behavioral risks associated with tattooing. Fam Med 2003;35: 52-54.

40 Benjamins LJ, Risser WL, Cromwell PF, Feldmann J, Bortot AT, Eissa MA, Nguyen AB: Body art among minority high school athletes: prevalence, interest and satisfaction; parental knowledge and consent. J Adolesc Health 2006;39: 933-935.

41 Preti A, Pinna C, Nocco S, Mulliri E, Pilia S, Petretto DR, Masala C: Body of evidence: tattoos, body piercing, and eating disorder symptoms among adolescents. J Psychosom Res 2006;61:561-566.

42 Iannaccone M, Cella S, Manzi SA, Visconti L, Manzi F, Cotrufo P: My body and me: self-injurious behaviors and body modifications in eating disorders preliminary results. Eat Disord 2013;21: 130-139.

43 Rooks JK, Roberts DJ, Scheltema K: Tattoos: their relationship to trauma, psychopathology, and other myths. Minn Med 2000;83:24-27.

44 Stirn A, Oddo S, Peregrinova L, Philipp S, Hinz A: Motivations for body piercings and tattoos - the role of sexual abuse and the frequency of body modifications. Psychiatry Res 2011;190:359-363. 
45 Nowosielski K, Sipiński A, Kuczerawy I, Kozłowska-Rup D, Skrzypulec-Plinta V: Tattoos, piercing, and sexual behaviors in young adults. J Sex Med 2012;9:23072314.

46 Kertzman S, Kagan A, Vainder M, Lapidus R, Weizman A: Interactions between risky decisions, impulsiveness and smoking in young tattooed women. BMC Psychiatry 2013;13:278.

47 Swami V, Pietschnig J, Bertl B, Nader IW, Stieger S, Voracek M: Personality differences between tattooed and nontattooed individuals. Psychol Rep 2012; 111:97-106.

48 Koch JR, Roberts AE, Armstrong ML, Owen DC: College students, tattoos, and sexual activity. Psychol Rep 2005;97: 887-890.

49 Swami V: Written on the body? Individual differences between British adults who do and do not obtain a first tattoo. Scand J Psychol 2012;53:407-412.

50 Guéguen N: Tattoo, piercing, and adolescent tobacco consumption. Int J Adolesc Med Health 2013;25:87-89.

51 Drews DR, Allison CK, Probst JR: Behavioral and self-concept differences in tattooed and nontattooed college students. Psychol Rep 2000;86:475-481.

52 Guéguen N: Tattoos, piercings, and alcohol consumption. Alcohol Clin Exp Res 2012;36:1253-1256.

53 Kozieł S, Sitek A: Self-assessment of attractiveness of persons with body decoration. Homo 2013;64:317-325.
54 Tiggemann M, Hopkins LA: Tattoos and piercings: bodily expressions of uniqueness? Body Image 2011;8:245-250.

55 Varma S, Lanigan SW: Reasons for requesting laser removal of unwanted tattoos. Br J Dermatol 1999;140:483-485.

56 Armstrong ML, Roberts AE, Koch JR, Saunders JC, Owen DC, Anderson RR: Motivation for contemporary tattoo removal: a shift in identity. Arch Dermatol 2008;144:879-884.

57 Shannon-Missal L: Los Angeles is America's 'Most Inked Market'. New York, NY, Harris Poll, 2014. http://www. harrisinteractive.com/vault/Harris\%20 Poll\%2032\%20-\%20MMQ\%20Tattoos_ 4.8.2014.pdf (accessed September 8, 2014).

58 Degelman D, Price ND: Tattoos and ratings of personal characteristics. Psychol Rep 2002;90:507-514.

-59 Hawkes D, Senn CY, Thorn C: Factors that influence attitudes toward women with tattoos. Sex Roles 2004;50:593604.

-60 Swami V, Furnham A: Unattractive, promiscuous and heavy drinkers: perceptions of women with tattoos. Body Image 2007;4:343-352.

61 Guéguen N: Effects of a tattoo on men's behavior and attitudes towards women: an experimental field study. Arch Sex Behav 2013;42:1517-1524.

62 Seiter JS, Hatch S: Effect of tattoos on perceptions of credibility and attractiveness. Psychol Rep 2005;96:1113-1120.
63 Wiseman DB: Perceptions of a tattooed college instructor. Psychol Rep 2010; 106:845-850.

64 Bekhor PS, Bekhor L, Gandrabur M: Employer attitudes toward persons with visible tattoos. Australas J Dermatol 1995;36:75-77.

65 Stuppy DJ, Armstrong ML, Casals-Ariet C: Attitudes of health care providers and students towards tattooed people. J Adv Nurs 1998;27:1165-1170.

66 Kluger N, Sleth JC: Perception of tattoos among physicians: the example of anesthesiologists, tattoos and epidural analgesia (poster 13). 1st European Congress on Tattoo and Pigment Research ECTP, Copenhagen, Nov 13-14, 2013.

67 Thomas CM, Ehret A, Ellis B, ColonShoop S, Linton J, Metz S: Perception of nurse caring, skills, and knowledge based on appearance. J Nurs Adm 2010; 40:489-497.

68 Westerfield HV, Stafford AB, Speroni KG, Daniel MG: Patients' perceptions of patient care providers with tattoos and/ or body piercings. J Nurs Adm 2012;42: 160-164.

69 Kluger N, Saarinen K: Aspergillus fumigatus infection on a home-made tattoo. Br J Dermatol 2014;170:1373-1375.

70 Tate JC, Shelton BL: Personality correlates of tattooing and body piercing in a college sample: The kids are alright. Pers Individ Dif 2008;45:281-285.

71 Kluger N: The risks of do-it-yourself and over-the-counter devices for tattoo removal. Int J Dermatol 2015;54:13-18.

Nicolas Kluger

Departments of Dermatology, Allergology and Venereology, Institute of Clinical Medicine University of Helsinki, Skin and Allergies Hospital, Helsinki University Central Hospital

Meilahdentie 2, PO Box 160

FIN-00029 HUS Helsinki (Finland)

E-Mail nicolaskluger@yahoo.fr 